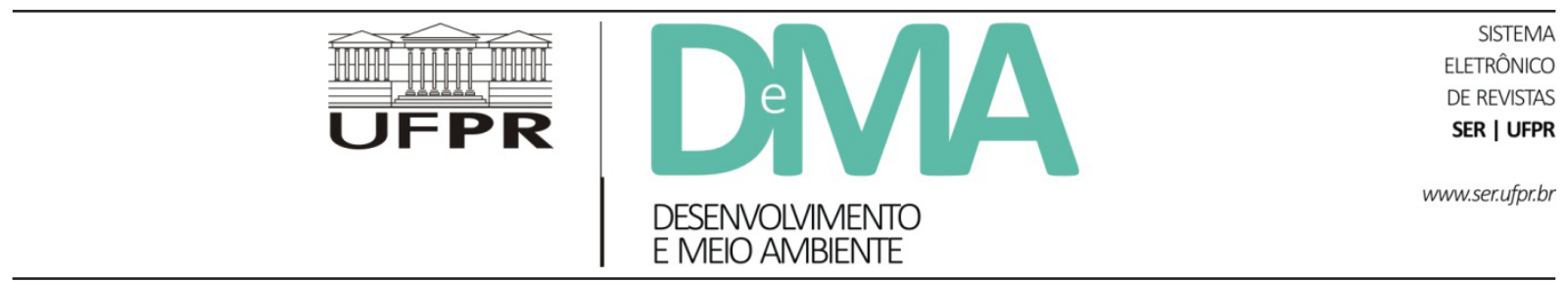

\title{
A problematização do local para a educação ambiental dos estudantes na educação básica
}

\section{The Problem of Place for Environmental Education Students in Basic Education}

\author{
Franciely Ribeiro dos $\mathrm{SANTOS}^{1 *}$, Ademir José ROSSO${ }^{1}$ \\ ${ }^{1}$ Programa de Pós-Graduação em Educação, Universidade Estadual de Ponta Grossa (UEPG), Ponta Grossa, PR, Brasil. \\ *E-mail de contato: francielyribeirosantos@gmail.com
}

Artigo recebido em 19 de novembro de 2015, versão final aceita em 13 de maio de 2016.

RESUMO: Este artigo tem como objetivo investigar junto com os estudantes do sexto ano do Ensino Fundamental (EF) e do terceiro ano do Ensino Médio (EM) os principais problemas socioambientais locais e suas possibilidades de encaminhamento das atividades de EA. A pedagogia crítica (Freire) e a epistemologia genética (Piaget) dialogam acerca do processo de construção do conhecimento socioambiental. A pesquisa investigou 717 estudantes de escolas das redes pública e privada por meio de questionários semiestruturados. Tabuladas e categorizadas, as informações foram analisadas no software SPSS. Estabeleceu-se uma análise comparativa dos problemas socioambientais apontados a partir das variáveis: rede, modalidade de ensino, sexo e bairro. As análises indicam que os estudantes, tanto do EF quanto do EM, enfatizam a problemática ambiental a partir dos problemas sociais.

Palavras-chave: problemas socioambientais; local; educação crítica; epistemologia genética.

ABSTRACT: This article aims to investigate along with students of the sixth grade of elementary school (EF) and the third year of high school (MS) the main local environmental problems and routing possibilities of EA activities. Critical theory (Freire) and the genetic epistemology (Piaget) dialogue about the construction of the environmental knowledge process. The research investigated 717 students from public and private schools through semistructured questionnaires. Tabulated and categorized the data were analyzed using SPSS software. Established a comparative analysis of the environmental problems identified from the variables: network, type of education, genre and neighborhood. The analyzes indicate that students from both the EF as EM emphasize environmental issues from social problems.

Keywords: social and environmental problems; place; town critical education; genetic epistemology. 


\section{Introdução}

Porque sou um ser no mundo e com ele, tenho não um pedaço imediato do suporte, mas possuo o meu mundo mais imediato e particular: a rua, a cidade, o país, o quintal da casa onde nasci [...] (FREIRE, 2006, p. 23-24, grifo do autor).

O estudo do lugar ou do meio "pode ser compreendido como um método de ensino interdisciplinar" (Lopes \& Pontuschka, 2009, p. 173), tanto no Ensino de Geografia (EG) (Callai, 2005; Cardoso, 2009; Bueno, 2009) quanto na Educação Ambiental (EA) (Loureiro, 2006). Além de desafiar o universalismo abstrato arraigado nas práticas escolares, esse método instiga, também, o localismo e esporádico. $\mathrm{O}$ primeiro é criticado por ignorar o local; no dizer de Freire (2006, p. 25), "ninguém se torna local a partir do universal". E o segundo, lembrado por Santos (1996, p. 258), porque "cada lugar é, à sua maneira, o mundo". Os reclames apontam para a interdependência espacial e hermenêutica do local para superar as ausências do modelo educativo universalista (McLaren, 1997), que estrutura a transmissão de conteúdos e a memorização de textos didáticos. Tais práticas limitam o aprendizado a fragmentos de informação insignificantes e desconexos frente às suas realidades (Freire, 1996). O estudo do meio/lugar é uma alternativa para transpor tal prática por meio dos seguintes fatores: problematização e superação da percepção naturalizada do ambiente (Cavalcanti, 2010); vivência de "uma prática educativa que reconhe(ce) a pesquisa como um princípio não só científico, mas, também, educativo" (Cardoso, 2009, p. 713); ampliação do rigor teórico e metodológico do referencial do processo de ensino e aprendizagem (Callai, 2005); busca da "complexidade de um espaço determinado extremamente dinâmico e em constante transformação" (Lopes \& Pontuschka, 2009, p. 173).
Algumas pesquisas associam-se à percepção do meio (Monteiro de Oliveira, 2006; Lestinge \& Sorrentino, 2008; Cardoso, 2009), agregadas às estratégias de sensibilização e conscientização presentes no EG e na EA (Reigota, 1998; Melazo, 2005; Gumes, 2005). O interesse de pesquisadores, professores e acadêmicos pela percepção relacionada ao estudo do meio/lugar é constatado pelo número de citações que eles fazem dessas obras. $\mathrm{O}$ estudo da percepção se deve ao fato de possibilitar-nos compreender a relação dos seres humanos com o meio ambiente (Kuhnen, 2011, p. 250), pois é por meio da experiência sensório-motora e das interações sociais que construímos possibilidades de avaliações, impressões e significados sobre uma determinada realidade (Fischer, 1994). Portanto, a percepção está associada às atividades que se estabelecem por meio da experiência cotidiana, isto é, no contato com o mundo (Tuan, 1980). A percepção ambiental sempre faz alusão a uma ação cotidiana (Piaget, 2013), nem sempre problematizada e reflexiva (Freire, 2005), por isso é parte integrante do processo de construção do conhecimento. A percepção sinaliza as relações entre seres humanos $\leftrightarrow$ meio ambiente e permite "conhecer como as pessoas se relacionam com o ambiente e suas mudanças, gerando compreensões sobre as influências das características ambientais sobre o comportamento das pessoas", e dessas pessoas com o meio em que estão inseridas (Kuhnen, 2011, p. 262).

No entanto, a abordagem da percepção a partir das aproximações entre a epistemologia genética e Paulo Freire sublinha o papel ativo do sujeito na construção do conhecimento, mediado pelo conflito cognitivo, pela problematização socioambiental do bairro em que ele mora. A percepção é assumida como parte do processo de construção do conhecimento, porém, é na sua superação que a construção 
do conhecimento se efetiva (Serpe et al., 2011). O conflito cognitivo (Piaget, 1975; 2013) ou a problematização (Freire, 2005) favorece a descentração e a tomada de consciência.

Apesar de o bairro, as ruas, as casas, as questões socioambientais estarem presentes na vida dos estudantes (Meyer, 1991) e poderem ser explorados como situações sentidas e percebidas por eles, as rotinas docentes raramente os incluem. Todavia, os estudantes não deixam suas histórias e expectativas fora dos muros da escola, como imagina a educação bancária (Freire, 1996; McLaren, 1997). Como consequência, a naturalização do meio e do cotidiano, em momentos e circunstâncias nos quais os riscos são minimizados, passa a ser vista como normal, "e a gravidade não se explicita em função de sua imediaticidade deslocada, muitas vezes, da perspectiva de longo prazo e dos fenômenos globais" (Loureiro, 2006, p. 131-132).

Assim, a inclusão do estudo do meio ou do espaço local, problematizado e dialogando com o espaço global, coloca-se como essencial para a construção dos conhecimentos geográfico e socioambiental necessários à EA. No artigo, indagamos sobre os problemas socioambientais levantados pelos estudantes da Educação Básica e suas implicações na problematização da Educação Ambiental crítica. Para isso, buscamos investigar junto com os estudantes do sexto ano do Ensino Fundamental (EF) e do terceiro ano do Ensino Médio (EM) os principais problemas socioambientais locais e suas possibilidades de encaminhamento das atividades de EA.

\section{O estudo do local e a educação ambiental}

O objetivo da EA é desenvolver a capacidade de "analisar as complexas relações entre processos naturais e sociais, para atuar no ambiente com uma perspectiva global, mas diferenciada pelas diversas condições naturais e culturais" (Leff, 2001, p. 256). Com esse objetivo, se explicita como a estreita relação entre o global e o local envolve os conceitos de lugar, cotidiano e cidadania (Hintz et al., 2014, p. 1138). A globalização levou-nos a uma nova relação com o mundo, pois, apesar de vê-lo por inteiro, tornou-se estranho (Santos, 1996). Se a racionalidade técnico-científica permitiu explorar o fundo dos oceanos e o sistema solar, as relações seres humanos $\leftrightarrow$ meio ambiente $\leftrightarrow$ seres humanos se dissociaram. E nessa complexidade estão os lugares, que "podem ser vistos como um intermediário entre o Mundo e os Indivíduos". Nisso se fundamenta a urgência de revisitar o lugar no mundo atual, de nele descobrir novos significados pela EA (Loureiro, 2006).

As escolas da educação básica têm sido eleitas como os principais locais de estudo e prática das políticas de EA, mas dificilmente essas políticas são identificadas em tais espaços. E, apesar dos mais de vinte anos da sua implementação, a problemática socioambiental ainda se encontra desconexa em relação à realidade dos estudantes. Tratada como uma obrigação curricular, é lembrada em datas comemorativas do calendário cívico, como o Dia da Árvore, ou o Dia da Água e do Meio Ambiente. Diante de tais desafios e questionamentos, a EA tem encontrado na teoria crítica os fundamentos para repensar-se. Em seu transcurso, passou por reflexões teórico-práticas inicialmente marcadas pela pluralidade teórica, podendo ser delimitada em três macrotendências: a conservacionista, a pragmática e a crítica (Layrargues, 2012).

A macrotendência conservacionista, que é influenciada pela corrente ecológica, fundamenta suas discussões nas ciências naturais. Sua visão de mundo é construída a partir da biologia e tende "a destacar os aspectos naturais ou ecológicos dos problemas ambientais em detrimento de seus aspectos 
sociais, políticos, econômicos e culturais". (Lima, 2009 , p. 153). Sua discussão promove a dicotomia homem x natureza e sua lógica é marcada pelo mecanicismo e pelo racionalismo (Lima, 2009). Nessa perspectiva, os saberes tradicionais populares são excluídos, pois tanto o desenvolvimento humano como a mudança de comportamento são tidos como individuais (Lima, 2009; Layrargues \& Lima, 2011).

A perspectiva pragmática apresenta-se na ideia de educação para o desenvolvimento e o consumo sustentáveis. Está focada no lixo, na coleta seletiva, e fundamentada na racionalização do padrão de consumo. Essa concepção é alimentada pela mídia e advém daí a dificuldade de "superar o pensamento e ação pragmática atualmente hegemônica na EA, em especial na sua dimensão informal" (Layrargues, 2012).

$\mathrm{Na}$ contramão dessas correntes está a EA crítica, de característica popular e emancipatória, fundamentada na perspectiva pedagógica de Paulo Freire, a qual tem como elemento de destaque a crítica à razão moderna (Lima, 2009). Assim como em Freire, a EA crítica defende uma abordagem problematizadora da realidade, envolvendo o domínio do conhecimento em diferentes escalas, numa relação global $\leftrightarrow$ local e no contexto dos espaços, os quais são descontextualizados na EA conservadora. Como afirmam Kuhnen \& Higuchi (2009, p. 101), “conhecer o contexto ambiental no qual o comportamento ocorre pode indicar como os significados relativos ao ambiente são incorporados e como se dá a aprendizagem". Para isso, destaca-se a importância do ambiente escolar em conhecer os interesses e desafios oriundos das realidades dos estudantes e a eles postos, uma vez que o lugar (o município de Ponta Grossa, no caso da presente pesquisa), relembrando Santos (1996, p. 252), “é, à sua maneira, o mundo". É importante, também, verificar que o mundo apresenta diferenças estruturais, econômicas e sociais e como ele as apresenta.

Se tomarmos a objetivação do lugar no EG, sabe-se que a Geografia "não se ensina, ela se constrói, ela se realiza". (Cavalcanti, 2008, p. 28). Para a referida autora, entre as preocupações teóricas estão algumas indicações que norteiam a boa prática do EG na contemporaneidade, entre as quais destacamos: a) "reiteração do espaço como dimensão espacial importante: é a vida cotidiana; [...] estudar o lugar para compreender o mundo"; b) potencialização do raciocínio espacial complexo, articulação local-global, "interdependência dialética entre local e global"; c) elaboração de conceitos geográficos, levando em consideração o fato de que "a formação de conceitos pressupõe encontro e confronto entre conceitos cotidianos e conceitos científicos"; e d) "Educação Ambiental e preocupação com o conceito de ambiente e ambiência, com a questão ambiental e qualidade de vida" (Cavalcanti, 2008, p. 31-33). No entanto, para isso é preciso mais do que a exposição de conteúdo. Os estudantes precisam aprender modos de pensamento e ação que permitam o desenvolvimento de capacidades, tais como: "atitude indagadora", "análise da realidade" e consideração de "diferentes escalas" (p. 34). Esses aspectos metodológicos inserem o estudante como sujeito no centro do processo de construção do conhecimento.

Assim como Cavalcanti (2008), Resende (2007) também valoriza o saber do aluno no ensino de Geografia. E, ainda, revela sua preocupação ante a situação em que os estudantes, principalmente os das classes sociais mais desfavorecidas, são considerados neutros, ou seja, "sem vida, sem cultura, sem história". Ao recusar o espaço histórico e geográfico do estudante, a escola marginaliza "o próprio aluno como sujeito do processo de conhecimento, transformando-o em objeto desse processo" 
(Resende, 2007, p. 84). Já a educação crítica, como se viu, defende uma educação escolar transformadora, voltada para a formação de sujeitos críticos e autônomos (Giroux, 1986; Freire, 1996; McLaren, 1997). Por isso, os desafios da educação e da EA escolar estão na negação da "neutralidade dos sujeitos escolares no processo de ensino e aprendizagem no qual se encontram inseridos" (Torres et al., 2014 p. 15) e na recusa do conhecimento "como um produto isolado de significado" (McLaren, 1997, p. 249). Tal posicionamento implica, certamente, um processo de formação crítica do estudante, ressaltando-se o fato de que, antes de se tornar crítico, o conhecimento precisa ser significativo (Giroux, 1986): "Ignorar as dimensões ideológicas da experiência do aluno significa negar a base sobre a qual os estudantes aprendem, falam e imaginam" (McLaren, 1997, p. 249).

Freire (2005) fundamenta sua teoria na correlação do eixo da educação problematizadora com o eixo do diálogo, constituídos em uma relação de confiança, horizontal, contrapondo-se à educação bancária. Para o autor (Freire, 2005, p. 95), “não há o diálogo verdadeiro se não há nos sujeitos um pensar verdadeiro. Pensar crítico". Nessa perspectiva, o diálogo e os conteúdos programáticos não podem ser construídos pela transmissão de um saber particular do professor. O diálogo começa quando o professor questiona o currículo escolar ante os conhecimentos prévios e a realidade vivida por seus alunos. Portanto, o conteúdo do diálogo está entre os conteúdos programáticos organizados pelo professor, e não apenas nos temas levantados pelos estudantes. Nessa dinâmica, o ato de educar não é estabelecido, imposto, mas construído. Os conteúdos programáticos representam o ponto de partida para a delimitação dos referidos temas.

A investigação do universo temático parte da ação, do diálogo entre professores $\leftrightarrow$ estudantes $\leftrightarrow$ espaço vivido, no contraponto, e apoiado, não determinado, pelos conteúdos programáticos. Por isso, o tema gerador não é uma hipótese, pois não parte da necessidade de verificação da sua existência, mas a discussão da relação vivida entre seres humanos $\leftrightarrow$ mundo $\leftrightarrow$ seres humanos. A capacidade de pensar e refletir sobre o meio em que estamos inseridos nos permite identificar e compreender nosso campo de ação, em circunstâncias nas quais se passa do subsistir para o coexistir, pois "no momento em que a percepção crítica se instaura, na ação mesma, se desenvolve um clima de esperança e confiança" que permite aos seres humanos se engajarem na superação das "situações-limites" (Freire, 2005, p. 105). Ao buscar na práxis o fundamento para a transformação do mundo, defende-se a ideia de que o discurso esvaziado de prática é constituído apenas por palavras desconexas, que impossibilitam o diálogo. Na perspectiva da educação crítica, o sujeito não é neutro, mas ontológico, epistêmico e coletivo. A ênfase na ação aposta que "existir, humanamente, é pronunciar o mundo, é modificá-lo" (Freire, 2005, p. 90). Para isso, é preciso que os estudantes cresçam em ambientes que permitam o exercício de "pensar, de indagar-se e de indagar, de duvidar, de experimentar hipóteses de ação [...]. As crianças precisam ter assegurado o direito de aprender a decidir, o que se faz decidindo" (Freire, 2000, p. 58-59).

Quanto à dimensão didática, a investigação temática parte do conhecimento prévio instaurado na problematização. Com isso, a ruptura na relação método-conteúdo permite um ambiente dialógico e problematizador, a partir da concepção de continuidade-ruptura-continuidade. Desse ambiente fazem parte outros dois processos - o de codificação e o de descodificação -, os quais interferem na forma como os estudantes percebem o meio em que estão inseridos. As codificações devem ampliar 
sua complexidade gradativamente. São "objetos cognoscíveis, desafios sobre os quais deve incidir a reflexão crítica dos sujeitos decodificadores". Já a descodificação representa "um ato cognoscente" realizado pelos descodificadores, o qual "recai sobre uma representação de uma situação concreta", permitindo o desenvolvimento de novos conhecimentos (Freire, 2005, p. 127).

O diálogo ocorre na horizontalidade da relação estudante $\leftrightarrow$ professor e por isso não pode ser confundido com a dinâmica escolar ainda vigente, em que o professor fala e os estudantes escutam; não se reduz a um ato de depositar ideias, ou ainda de simples trocas de ideias. É um ato de fé nos seres humanos, estabelecido por relações de confiança. A ação do professor é de mediador, e não de um impositor de ideias, ou conceitos prontos que para ele são importantes (Freire, 1996; 2005). Portanto, a relação entre educador e educando deve ser dialética e problematizadora, pois a autêntica educação ocorre de A com B, mediatizados pelo mundo, e não de A para B (Freire, 2005, p. 118). No diálogo, "estudantes e professores trabalham como parceiros em uma busca conjunta pela 'consciência crítica', levando à transformação humana do mundo, em vez de uma acomodação ao próprio mundo" (McLaren, 1997, p. 257).

Delval (2007) corrobora o que diz Freire, ao afirmar que a escola atual é insatisfatória, uma vez que, além de não aproveitar o potencial dos estudantes para a aprendizagem, realiza a transmissão dos conhecimentos de forma precária, pobremente. $\mathrm{O}$ autor reafirma questionamentos quanto ao papel da escola e do aprender, ao questionar o processo avaliativo: "Na escola, o que mais as crianças aprendem é interpretar os desejos do professor e saber o que se espera delas nos exames. O êxito não está tanto em saber a matéria, mas no que deve dizer e como se deve dizer" (Delval, 2007, p. 35). Nesse sentido, o professor necessita deixar de ser "apenas um conferencista"; ele deve estimular a "pesquisa e o esforço, ao invés de se conectar com a transmissão de soluções já prontas" (Piaget, 1973, p. 18).

O exame do papel da percepção na construção dos conhecimentos socioambientais necessários à EA, numa primeira aproximação teórica entre Freire e Piaget, mostra que "as ações que transformam o mundo são correlativas às ações que transformam o sujeito" (Becker, 2012, p. 38), pois "O mundo não é. O mundo está sendo. [...] Ninguém pode estar no mundo, com o mundo e com os outros de forma neutra" (Freire, 1996, p. 76-77). O movimento é intermediado por um sujeito e um objeto. Mas quem é esse sujeito na teoria de Piaget? "Sujeito é esse centro ativo, $[. .$.$] cognitivo de tomada de$ consciência, [...] ao agir sobre o mundo, sobre o outro, sobre o diferente, sobre o oposto - sobre o objeto -, busca aí o alimento de sua transformação" (Becker, 1999, p. 74).

A ação é o motor que move a produção do conhecimento, mas é o conflito cognitivo a descentração, a matriz energética que alimenta o processo de assimilação e acomodação, ou seja, a adaptação. A assimilação envolve a transformação dos objetos, enquanto a acomodação implica transformação do sujeito, dos seus esquemas e estruturas.

\begin{abstract}
Objeto é o meio físico e social: é o mundo dos objetos materiais e das relações sociais; das coisas materiais, mas também dos conceitos, das imagens e das linguagens; o mundo da natureza, dos ecossistemas, das diferentes manifestações da vida; da sociedade, da cultura, das artes, das ciências; das percepções, sensações, topologias, movimentos; enfim, do que está aí passível de sofrer transformações pela atividade do sujeito (Becker, 1999, p. 73).
\end{abstract}

Ao propormos a superação da percepção como estratégia de ensino para os problemas socioambien- 
tais, tomamos como base a seguinte afirmativa de Piaget (1979, p. 10): "Entre as gêneses sem estrutura [...] e as totalidades ou formas sem gênese que arriscam assim, sem cessar, a reunir-se ao terreno transcendental das essências, das ideias platônicas [...] é chamado a escolher ou a encontrar soluções de superação". A percepção, assim como a linguagem e o contexto, é elemento imprescindível, mas de interferência relativa (Rosso, 1998, p. 64). Ao inserir a percepção numa situação didático-pedagógica, os professores indicam preocupações em relação ao ensino enquanto simples transmissão. Isso aparece quando eles assumem estratégias metodológicas que buscam retirar os estudantes do ambiente da sala de aula, como saída de campo, passeio pelo bairro ou museu, entre outras. Contudo, tais iniciativas revelam a necessidade de aprofundamento teórico, pois, apesar de bem intencionadas, nem sempre alteram as relações pedagógicas e ampliam a participação e o envolvimento dos estudantes (Piaget, 1985).

A construção de conhecimentos resulta de um processo sucessivo de assimilações e acomodações que buscam um equilíbrio não permanente, mas temporário. Diante de uma novidade ou dúvida do sujeito em relação ao objeto ou ao meio, pode ocorrer o desequilíbrio e a busca por um novo equilíbrio. Por ser dinâmico, esse processo é denominado de equilibração (Piaget, 1975). A construção de conhecimento é movida por incompatibilidades momentâneas e conflitos que devem ser ultrapassados para chegarem a um nível de equilíbrio mais elevado (Piaget, 2013). A equilibração corresponde, portanto, a uma "sucessão de determinadas estratégias [...]. Esta sucessão exige uma abstração sui generis que permite a passagem de uma estrutura menos geral a uma estrutura mais geral" (Battro, 1976, p. 320; grifo do autor).

A importância do conflito cognitivo está no processo, que envolve rupturas paradigmáticas na construção do conhecimento científico e educacional (Serpe et al., 2011). Não há determinação prévia no meio e no sujeito, porquanto o desenvolvimento cognitivo não é determinado, por isso não é acumulativo. No entanto, é definido na experiência por meio da história, da interação de cada um. Aprender significa conhecer, "não é mera percepção e representação". O conhecimento exige ação e operação, pois o aspecto operatório é construído na ação, e não na percepção (Severino, 1994, p. 15; 19). Isso porque a percepção constitui "uma forma particularmente clara de comportamento acomodativo, sendo a acomodação uma atividade voltada para fora da adaptação inteligente, que aplica os esquemas gerais à situação especial do 'aqui-e-agora"" (Furth, 1974, p. 160). E o conhecimento derivado da relação entre sujeito e meio é bastante amplo, não pode ficar apenas no "aqui-e-agora", uma vez que abrange tanto a natureza como os objetos, as ideias e os valores.

\section{Procedimentos metodológicos e analíticos}

Esta é uma pesquisa qualitativa e quantitativa (Lakatos \& Marconi, 2006). Utiliza instrumento estatístico para análise cruzada e de correlação entre as variáveis (rede de ensino, modalidade de ensino, sexo, bairro, problemas ambientais e problemas sociais), assim como análise de conteúdo, de caráter exploratório-descritivo, para a categorização dos problemas socioambientais do bairro, indicados pelos estudantes (Bardin, 2002). A abordagem quantitativa está relacionada às análises cruzadas e correlacionadas, comparativas e estatísticas, realizadas pelo software SPSS (Statistical Package for Social Sciences - Pacote Estatístico para as Ciências Sociais). As análises foram efetuadas com a operação estatística Crosstab (tabela de referência cruzada), que possibilitou cruzar as 
seguintes variáveis: rede de ensino, modalidade de ensino (EF e EM), sexo, bairro (local de moradia dos estudantes), problemas ambientais e sociais. $\mathrm{O}$ cruzamento permitiu a verificação da distribuição e o agrupamento dos estudantes conforme as variáveis que processam as informações estruturadas de forma numérica em variáveis que, organizadas em tabelas, indicam a frequência (f) e a porcentagem (\%) das informações. Além da Crosstab, também foi utilizada a análise de correlação, para assim compreender como e de que forma acontece a integração dos estudantes com as variáveis de análise (Serpe, 2015). Segundo Pocinho \& Figueiredo (2013, p. 5), a análise de correlação "testa a interdependência entre as variáveis e a intensidade da correlação entre elas".

$\mathrm{O}$ instrumento utilizado para coletar as informações foi o questionário semiestruturado. Sua aplicação ocorreu entre os meses de junho e agosto de 2014. Participaram quatro escolas da rede pública e duas da rede privada de ensino, somando 717 estudantes do município de Ponta Grossa-PR. Os questionários foram aplicados no sexto ano do EF e no terceiro ano do EM. Neste momento, apresentaremos um recorte de seis questões, sendo quatro sobre dados censitários (rede de ensino, modalidade de ensino, sexo e bairro) e duas sobre os conhecimentos quanto aos problemas socioambientais do bairro.

Destacamos que o preenchimento dos questionários foi realizado pelos estudantes de forma individual, mediante a orientação de que os mesmos não seriam analisados individualmente e de que $o$ objetivo da investigação não era avaliativo, mas sim mapear os problemas socioambientais do bairro em que moram, conforme seus saberes. Os estudantes foram orientados a deixar questões em branco, caso não soubessem responder. Na Tabela 1 apresentamos o perfil dos estudantes, frequência e porcentagem, em relação às seguintes variáveis: rede de ensino, modalidade de ensino, sexo e bairro em que residem.

TABELA 1 - Perfil dos estudantes participantes da pesquisa

\begin{tabular}{cccc}
\hline Variável & Subcategoria & $\begin{array}{c}\mathbf{N}^{\mathbf{0}} \mathbf{d e} \\
\text { estudantes (f) }\end{array}$ & $\mathbf{\%}$ \\
\hline \multirow{2}{*}{ Rede de Ensino } & Pública & 386 & 53,8 \\
& Privada & 331 & 46,2 \\
\hline Modalidade de & Ensino Fundamental & 323 & 45 \\
Ensino & Ensino Médio & 394 & 55 \\
\hline \multirow{2}{*}{ Sexo } & Masculino & 352 & 49,1 \\
& Feminino & 359 & 50,1 \\
& Não informaram & 6 & 8 \\
\hline \multirow{2}{*}{ Bairro } & Centro & 55 & 7,7 \\
(Local de & Periferia 1 & 350 & 48,8 \\
moradia) & Periferia 2 & 183 & 25,5 \\
& Periferia 3 & 39 & 5,4 \\
& Distritos & 16 & 2,2 \\
Total & Não informaram & 74 & 10,3 \\
\hline FONE: Osauto & & $\mathbf{7 1 7}$ & $\mathbf{1 0 0}$ \\
\hline
\end{tabular}

FONTE: Os autores.

A diferença de questionários aplicados entre estudantes de escolas públicas e privadas foi menor que $10 \%$. As escolas da rede pública $(\mathrm{N}=4)$ estão localizadas no Centro $(\mathrm{N}=2)$, Periferia $1(\mathrm{~N}=1)$ e Periferia $2(\mathrm{~N}=1)$. Já as escolas privadas $(\mathrm{N}=$ 2) estão na área central da cidade, sendo uma laica e outra religiosa. Quanto à modalidade de ensino, houve a participação de estudantes do sexto ano do EF $(\mathrm{N}=323)$ e do terceiro ano do EM $(\mathrm{N}=394)$. A escolha do sexto ano do EF e do terceiro ano do EM está nas suas características escolares. São estudantes que estão iniciando a educação básica 2 , pré-adolescentes, e estudantes concluintes do EM que estão se encaminhando para o ensino superior ou para o mercado de trabalho. Estão em transição de etapas em suas vidas quanto aos aspectos que tangem ao crescimento físico, intelectual e afetivo. Quanto ao sexo, a diferença foi apenas de 1\% entre os sujeitos investigados. 
Em relação à distribuição territorial, ou seja, ao bairro de residência dos estudantes no município de Ponta Grossa-PR, verificamos que praticamente a metade deles reside na Periferia $1(48,8 \%)$. A segunda concentração está na Periferia $2(25,5 \%)$. Em terceiro lugar está a área central, constituída por $7,7 \%$ dos alunos, e em seguida estão os Distritos, com $2,2 \%$ dos estudantes investigados ${ }^{1}$. Na Tabela 2 , podemos verificar a relação entre a distribuição espacial desses estudantes com o bairro de moradia. Essa classificação é feita obedecendo às áreas limítrofes do Centro para os Distritos.

A partir da Tabela 2, podemos verificar que o maior número de estudantes que não identificaram o bairro em que moram é de escola pública ${ }^{2}$ $(\mathrm{N}=51)$, do EF $(\mathrm{N}=53)$ e do sexo masculino ( $\mathrm{N}$ $=43$ ). Esse dado indica o distanciamento entre a educação escolar e o cotidiano, pois as dimensões espaciais deveriam constituir-se como conteúdos estruturantes no sexto ano do EF (Paraná, 2008). A concentração populacional da Periferia 1 está configurada por estudantes da rede privada $(\mathrm{N}=182)$, do EM $(\mathrm{N}=197)$ e do sexo feminino $(\mathrm{N}=187)$. Já a Periferia 2, com a segunda maior concentração de estudantes, difere da Periferia 1 devido aos fatores socioeconômicos que influenciam a ocupação espacial (Santos, 1996). Dos 183 estudantes que ocupam a Periferia 2, 109 são da rede pública, assim como os principais moradores da Periferia 3 e dos Distritos. Os estudantes da rede privada residem predominantemente no Centro e na Periferia 1. Quanto ao sexo, a variação mais significativa está na Periferia 1, habitada em maior número por estudantes do sexo feminino.

A análise cruzada (Crosstab) da existência e tipos de problemas socioambientais com as variáveis de pesquisa permitiu-nos um mapeamento estatístico, apresentado na Tabela 3.

Ao partirmos da categoria rede, identificamos que a maioria dos estudantes declarou a existência de problemas ambientais no bairro em que mora. A rede pública apresentou a maior ocorrência de problemas ambientais $(\mathrm{N}=225)$, mas também foi a que apresentou a maior frequência da inexistência de tais problemas $(\mathrm{N}=153)$. No entanto, ao justificar o problema ambiental, a maioria dos estudantes $(\mathrm{N}=354)$ deixou a questão em branco; além disso, alguns estudantes não conseguiram explicá-la ou a

TABELA 2 - Análise cruzada estatística da distribuição dos estudantes conforme a rede, a modalidade de ensino e o sexo com o bairro de moradia

\begin{tabular}{|c|c|c|c|c|c|c|c|c|c|c|c|c|c|c|c|}
\hline \multirow{2}{*}{\multicolumn{2}{|c|}{ VARIÁVEIS }} & \multicolumn{2}{|c|}{ S.I } & \multicolumn{2}{|c|}{ Centro } & \multicolumn{2}{|c|}{ Perif. 1} & \multicolumn{2}{|c|}{ Perif. 2} & \multicolumn{2}{|c|}{ Perif. 3} & \multicolumn{2}{|c|}{ Distritos } & \multicolumn{2}{|c|}{ Total } \\
\hline & & $F$ & $\%$ & $F$ & $\%$ & $F$ & $\%$ & $F$ & $\%$ & $F$ & $\%$ & $F$ & $\%$ & $F$ & $\%$ \\
\hline \multirow{2}{*}{ REDE } & Pública & 51 & 13,2 & 17 & 4,4 & 168 & 43,5 & 109 & 28,2 & 32 & 8,3 & 9 & 2,3 & 386 & 100 \\
\hline & Privada & 23 & 6,9 & 38 & 11,5 & 182 & 55,0 & 74 & 22,4 & 7 & 2,1 & 7 & 2,1 & 331 & 100 \\
\hline \multirow{2}{*}{ MODALIDADE } & $E F$ & 53 & 16,4 & 23 & 7,1 & 153 & 47,4 & 70 & 21,7 & 24 & 7,4 & $\mathbf{0}$ & 0 & 323 & 100 \\
\hline & $E M$ & 21 & 5,3 & 32 & 8,1 & 197 & 50 & 113 & 28,7 & 15 & 3,8 & 16 & 4,1 & 394 & 100 \\
\hline \multirow{2}{*}{ SEXO } & Masculino & 43 & 12,2 & 29 & 8,2 & 161 & 45,7 & 95 & 27 & 20 & 5,7 & 4 & 1,1 & 352 & 100 \\
\hline & S.I & 2 & 33,3 & 0 & 0 & 2 & 33,3 & 2 & 33,3 & 0 & 0 & $\mathbf{0}$ & 0 & 6 & 100 \\
\hline \multicolumn{2}{|c|}{ TOTAL } & 74 & 10,3 & 55 & 7,7 & 350 & 48,8 & 183 & 25,5 & 39 & 5,4 & 16 & 2,2 & 717 & 100 \\
\hline
\end{tabular}

S.I - Sem informação.

1 Mapa disponível em: <http://geo.pg.pr.gov.br/webgis/map.phtml. Acesso em 16/08/2015>.

2 Levantamentos estatísticos apontaram que se tratava de estudantes do sexto ano do EF. 
TABELA 3 - Análise cruzada das variáveis rede, modalidade e bairros com os problemas socioambientais

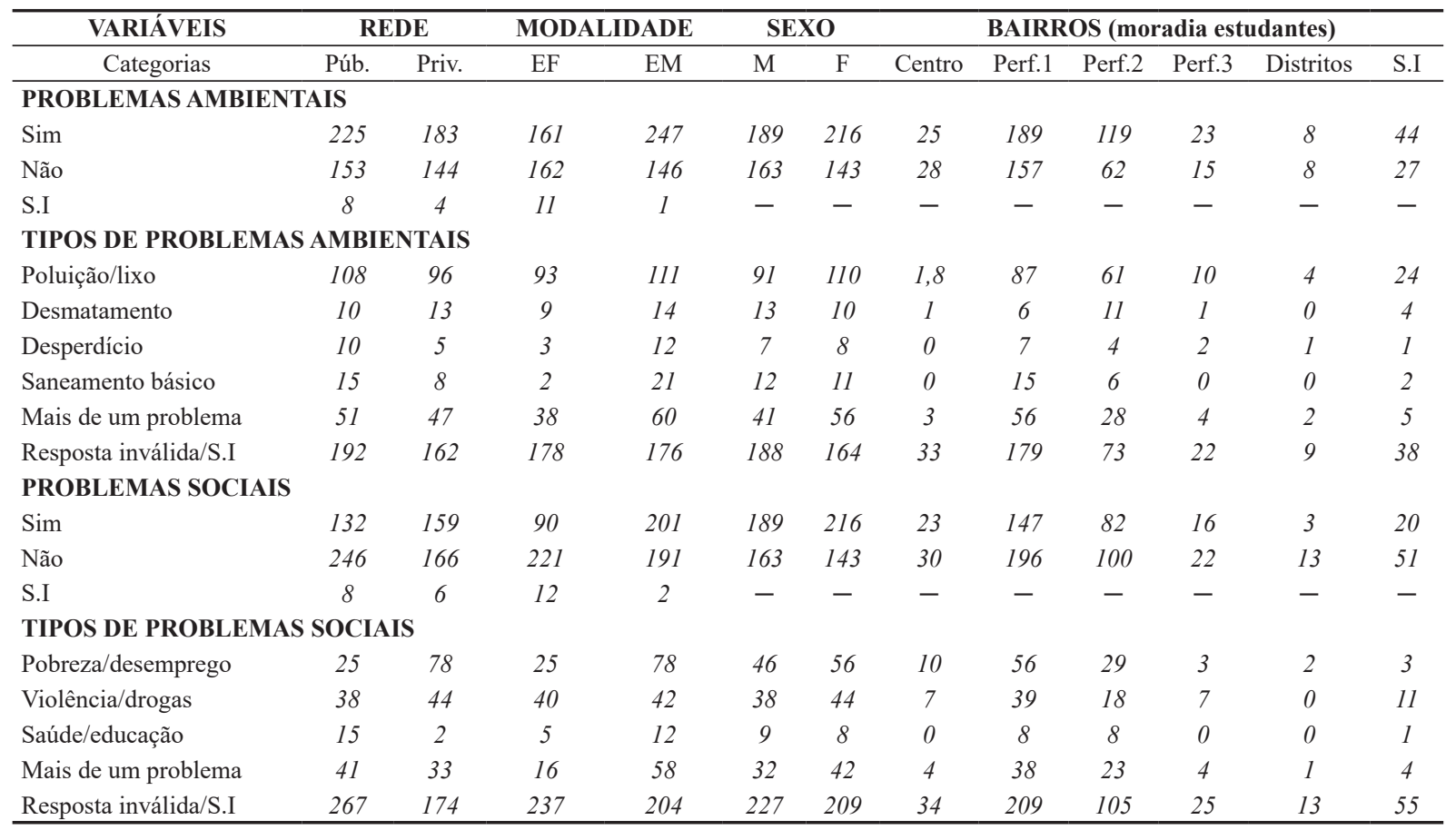

confundiram com questões sociais. Isso poderia ser atribuído ao pouco significado das questões para esses alunos ou ao fato de eles não conseguirem estabelecer conexões dos problemas ambientais com a realidade vivida; ou, ainda, à sua atitude de neutralidade frente à problemática socioambiental. Tal situação permite algumas perguntas sobre o processo de construção do conhecimento no ambiente escolar: Há, de fato, sujeitos no processo de ensino e aprendizagem? Os conteúdos são transformados em conhecimentos? Será que os estudantes atingem a assimilação, para que então possa haver acomodação? (Becker, 1999).

O problema que apresentou a maior frequência foi Poluição/Lixo $(N=204)$, sendo que foram os estudantes da rede pública $(\mathrm{N}=108)$ os que mais o citaram. Entre os problemas citados, estão a po- luição da água, do ar e dos solos, e o lixo. Mas é o lixo a problemática mais abordada. Entre as descrições, destacamos: "Pessoas sem conscientização ambiental, jogando lixo na rua, entupindo bueiros e causando enchentes"; "Abandono e descaso com os animais, lixo nas ruas, esgoto a céu aberto". Assim como nesta categoria, as demais justificativas foram muito curtas e objetivas. Poucos estudantes da rede pública $(\mathrm{N}=51)$ e privada $(\mathrm{N}=47)$ relacionaram mais de um problema ambiental. Os apontamentos refletem a orientação pragmática e conservacionista oriunda da mídia, dos materiais didáticos e do discurso dos professores (Lima, 2009; Layrargues, 2012).

Quanto à existência de problemas sociais, o número de estudantes que não respondeu à questão ou a confundiu com questões próprias do ambiente 
natural foi ainda maior $(\mathrm{N}=412)$, sendo 246 da rede pública e 166 da rede privada. Dos 717 estudantes investigados, apenas 132 da rede pública e 159 da rede privada indicaram a existência de problemas sociais no seu bairro. Mas, ao verificarmos a quantidade de estudantes que não conseguiram justificar a questão, nos deparamos com um valor expressivo de 441, dos quais 267 são da rede pública e 174 da rede privada de ensino. A distinta delimitação dos problemas ambientais pela maioria dos estudantes revela a dicotomia natureza $\mathrm{X}$ seres humanos, característica da tendência conservacionista (Lima, 2009), contrariando os objetivos da EA de analisar e compreender a complexa interação entre o social e o natural (Leff, 2001).

Os problemas sociais mais citados pelos estudantes foram os correspondentes às categorias Pobreza/Desemprego e Violência/Drogas. Entre os apontamentos, estão: "É possível perceber muito contraste social", "moradores de rua e pobreza"; "existe muita diferença social, muitas famílias com muitas dificuldades"; "drogas, bebidas alcoólicas e várias outras"; "tráfico de drogas e pessoas alcoólatras". A rede privada foi a que mais expôs tais questões, pois 78 estudantes destacaram a Pobreza/ Desemprego e 44 indicaram Violência/Drogas. Para esses estudantes, os problemas sociais são descritos da seguinte maneira: "No período noturno é perigoso, pois a taxa de assaltos é alta"; "pobreza em certos locais"; "desigualdade social e falta de infraestrutura suficiente para a quantidade de pessoas que moram no meu bairro"; "favelas"; "falta de dinheiro em algumas casas"; "drogas e violência".

A categoria Saúde/Educação foi mencionada em maior proporção pelos estudantes da rede pública, que destacaram a precariedade no atendimento dos postos de saúde, a falta de creches e de saneamento básico. Também foram os estudantes da rede pública $(\mathrm{N}=41)$ que relacionaram mais de um problema social, em contraposição aos da rede privada $(\mathrm{N}=33)$. Entre as descrições, apareceram: "Há lugares próximos a alguns arroios que não têm saneamento básico e asfalto"; "posto (de saúde) com atendimento muito precário"; "falta creche para as crianças". Os problemas sociais citados a partir da experiência vivida são apontados de maneira distinta entre os estudantes das redes pública e privada. Esses problemas revelam medos, inseguranças e insatisfações, reafirmando a falta de oportunidades de aprendizagem a partir das contradições e indagações advindas do espaço vivido (Freire, 2005; Resende, 2007; Cavalcanti, 2008).

Ao cruzar as informações a partir da variável modalidade, verificamos que foram os estudantes do EM os que mais identificaram problemas ambientais $(\mathrm{N}=247)$, em comparação com os do $\mathrm{EF}(\mathrm{N}=161)$. Dos que assinalaram não haver problemas ambientais em seu bairro, 151 são do EF e 146 do EM. Já em relação aos problemas sociais, constatamos que 412 estudantes indicaram a não existência de tais problemas no bairro onde moram, sendo que 221 são do EF e 191 do EM. Os que assinalaram a ocorrência desses problemas foram 90 do EF e 201 do EM. Quanto à justificativa, 354 estudantes nada responderam acerca da existência de problemas ambientais e 441 também não indicaram problemas sociais. O problema ambiental de maior destaque para a modalidade de ensino foi a Poluição/Lixo, assim como para os estudantes da variável rede. Entretanto, o segundo valor de destaque foi a justificativa referente a mais de um problema ambiental, apresentada por 60 estudantes do EM e 38 do EF. O problema social de maior relevância para os estudantes foi Pobreza/Desemprego $(\mathrm{N}=103)$, citado por 78 alunos do EM e 25 do EF. Depois aparece a variável Violência/Drogas $(\mathrm{N}=82)$, com indicações praticamente iguais para as duas modalidades de ensino: 40 estudantes do 
EF e 42 do EM. A variável Saúde/Educação foi apontada por apenas 17 estudantes, sendo que 12 deles são do EM.

A variável sexo revelou que a maior identificação da ocorrência de problemas ambientais coube à categoria $\mathrm{F}$ (sexo feminino): 216 meninas assinalaram haver problemas ambientais no bairro. As estudantes destacaram, em maior proporção, a Poluição/Lixo $(\mathrm{N}=110)$, e mais de um problema $(\mathrm{N}=56)$. Quanto à identificação dos problemas sociais, a proporção entre os meninos e as meninas foi a mesma dos problemas ambientais: 216 meninas marcaram sim em relação à ocorrência de problemas sociais e 189 meninos assinalaram não. As meninas foram as que mais apontaram problemas sociais como Pobreza/Desemprego $(\mathrm{N}=56)$, Violência/Drogas $(\mathrm{N}=44)$, e mais de um problema $(\mathrm{N}=42)$. A construção de conhecimentos a partir da experiência na interação com o local desafia as mulheres a transpor os obstáculos vivenciados no cotidiano. Por isso, elas adquirem "mais experiência na condução de um processo de desenvolvimento humano local e sustentável" (Tornquist, et al., 2010, p. 867).

A análise cruzada busca relacionar as variáveis quanto a sua distribuição, mas como estabelecer um parâmetro de significação ou medir a intensidade de correlação entre as informações? Na Tabela 4 apresentamos a análise de correlação bivariada.

Ao observarmos a Tabela abaixo, verificamos que a maior incidência de correlação parte da questão social, a qual, além de agregar o maior número de informações, também traz o maior número de correspondência entre as variáveis. Para compreendermos a correlação entre as variáveis, utilizamos a análise de frequência para quantificar as variáveis. Essa análise indicou a similaridade de problemas ambientais e sociais $(\mathrm{N}=408)$, assim como a sua inexistência $(\mathrm{N}=309)$. Entretanto, os problemas ambientais foram justificados por 363 estudantes e os problemas sociais por 276 (Tabela 3 ). Constatamos que a maior significância de correlação parte dos problemas sociais, principalmente dos tipos de problemas sociais, em relação aos quais foram correlacionadas cinco variáveis - rede de ensino, modalidade de ensino, bairro em que mora, problemas ambientais do bairro e tipos de problemas ambientais.

Diante da análise apresentada, reconhecemos que os estudantes correlacionam a problemática ambiental a partir do social. Isso revela um gap entre professores e estudantes, pois os professores tratam da EA a partir de aspectos parciais da realidade, com enfoque conservacionista, em que os

TABELA 4 - Análise de correlação - corpus Estudantes (6 $6^{\circ}$ ano do EF e $3^{\circ}$ do EM)

\begin{tabular}{|c|c|c|c|c|c|c|c|c|}
\hline ESTUDANTES N $=717$ & 1 & 2 & 3 & 4 & 5 & 6 & 7 & 8 \\
\hline 1. Sexo & - & & & & & & & \\
\hline 2. Rede de Ensino &, $114^{* *}$ & - & & & & & & \\
\hline 3. Modalidade de Ensino & &, $074^{*}$ & - & & & & & \\
\hline 4. Bairro/Vila & & &, $154^{* *}$ & - & & & & \\
\hline 5. Problemas ambientais do bairro que mora & & &,$- 129^{* *}$ & & - & & & \\
\hline 6. Tipos de problemas ambientais & & & & &, $709^{* *}$ & - & & \\
\hline 7. Problemas sociais do bairro que mora & & &,$- 129^{* *}$ & & $1,000^{* *}$ &, $709^{* *}$ & - & \\
\hline 8. Tipos de problemas sociais citados & &,$- 231^{* *}$ &,$- 180^{* *}$ & &, $241^{* *}$ &, $178^{* *}$ & $241^{* *}$ & - \\
\hline
\end{tabular}


seres humanos estão dissociados da natureza (Bortolozzi \& Filho, 2000) e os problemas ambientais complexos são tratados com atitudes simplistas, pragmáticas, como a coleta seletiva do lixo e o plantio de árvores (Layrargues, 2012). Como Bortolozzi \& Filho (2000, p. 167) ressaltam, "os problemas sociais ora são deixados de lado completamente, ora são ressaltados, mas sem uma contextualização histórico-espacial [...] (e) base física material".

Sobre os Problemas sociais do bairro em que mora, certificamos sua relação com a modalidade de ensino. Já os problemas ambientais do bairro em que mora e tipos de problemas ambientais estão relacionados às experiências vividas. Os estudantes os identificam a partir de situações que são incômodas, sejam elas experiências diretas ou indiretas. Confirma-se assim o pressuposto de Piaget, de que não existe percepção sem conhecimento operativo (Furth, 1974). O mapeamento dos problemas socioambientais indica possibilidades temáticas a serem exploradas com estudantes para a construção de conhecimentos críticos e reflexivos, superando a simples observação da paisagem (centração) para a compreensão global (descentração). Por conseguinte, é imprescindível que os problemas socioambientais mapeados, ou diagnosticados no ambiente escolar, sejam constituídos em conflitos cognitivos para se transformarem em objetos de compreensão e construção de conhecimento.

\section{Considerações finais}

A análise das informações realizadas para este estudo nos permitiu conhecer uma parcela da realidade dos estudantes da educação básica do município de Ponta Grossa-PR. O número de sujeitos investigados (717) nos permitiu analisar a contribuição de 315 estudantes. As análises cruza- das e de correlação (SPSS) nos permitiram mapear a identificação dos problemas socioambientais, seus tipos e verificar como esses problemas estão correlacionados pelas variáveis rede, modalidade, sexo e bairro. Possibilitaram-nos, também, compreender a correlação, a interdependência e o significado entre as variáveis.

A análise de correlação identificou que a maioria dos estudantes ocupa as Periferias 1 e 2, somando 533 deles. A ocupação territorial indicou a influência dos fatores socioeconômicos. Os estudantes da rede privada concentram-se nas áreas próximas da área central, com acesso aos principais instrumentos urbanos, tais como escolas, comércios e hospitais. Já os estudantes da rede pública estão concentrados em maior proporção nas Periferias $2 \mathrm{e}$ 3. Constatou-se que 74 estudantes não identificaram o bairro em que moram, entre estes 51 da rede pública, 53 do EF e 43 meninos. Esse dado evidencia o distanciamento que há entre as disciplinas escolares, como a Geografia, com o cotidiano e as vivências dos estudantes, uma vez que a relação entre a organização, a distribuição e a interação espaciais são conteúdos que começam a ser trabalhados no final do EF 1 (quinto ano), reafirmados e aprofundados no sexto ano.

Quanto às variáveis rede e modalidade, verificou-se que os problemas ambientais e sociais identificados são similares, variando apenas a frequência em que são citados. O problema ambiental de maior destaque foi Poluição/Lixo e os problemas sociais foram Pobreza/Desemprego e Violência/Drogas. A variável sexo revelou que as meninas são as que mais identificaram os problemas sociais e ambientais. Quanto aos tipos de problemas, também foram as meninas as que mais contribuíram para a configuração das categorias Poluição/Lixo; Mais de um problema ambiental; Pobreza/Desemprego; Violência/Drogas; e Mais de um problema social. 
Esses dados mostram que as meninas tiveram uma contribuição mais significativa na identificação e nos apontamentos dos problemas socioambientais.

A análise de correlação contribuiu para que pudéssemos compreender o significado da interação das variáveis com a problemática socioambiental. A correlação nos permitiu verificar que os estudantes veem os problemas ambientais a partir das questões sociais e que essa visão revela que suas compreensões e suas estruturas cognitivas são influenciadas pelas suas experiências, pelo seu cotidiano. Contrária é a perspectiva dos professores ao trabalharem as questões socioambientais a partir dos enfoques pragmáticos e conservacionistas da EA.

$O$ estudo reafirma a necessidade de um trabalho pedagógico mais próximo da realidade do estudante. As informações indicam que os estudantes do EF apresentam dificuldades em explanar

\section{Referências}

Bardin, L. Análise de conteúdo. Lisboa: Edições 70, 2002.

Battro, A. M. O pensamento de Jean Piaget: psicologia e epistemologia. Rio de Janeiro: Forense Universitária, 1976.

Becker, F. O sujeito do conhecimento: contribuições da epistemologia genética. Educação \& Realidade, 24(1), 73-89, 1999. Disponível em: <http://www.seer.ufrgs.br/ educacaoerealidade/article/view/55807>.

Becker, F. Educação e construção do conhecimento. Porto Alegre: Penso, 2012.

Bortolozzi, A.; Filho, A. P. Diagnóstico da educação ambiental no ensino de geografia. Cadernos de Pesquisa, 109, 145-171, 2000. Disponível em: <http://www.scielo.br/pdf/ cp/n109/n109a07.pdf $>$.

BUENO, M, A. A importância do estudo do meio na prática de ensino em geografia física. Boletim Goiano de Geografia, 29(2), 185-198, 2009. Disponível em: <http://www.redalyc. org/articulo.oa?id=337127152013>. os problemas ambientais e sociais. Dessa forma, reiteramos, com Loureiro (2006) e Layrargues (2012), a necessidade de ampliar a crítica do ensino destacando a realidade vivida que é passível de ser contextualizada e melhor explorada pelo próprio professor. A constituição de um ambiente escolar que propicia a educação crítica está fundamentada na ação, na interação do sujeito com seu ambiente e objeto de conhecimento.

\section{Agradecimentos}

Os autores agradecem a Comissão de Aperfeiçoamento de Pessoal do Nível Superior (Capes) e a Fundação Araucária (FA) pela concessão de bolsa de estudo, doutorado, ao Programa de Pós-Graduação em Educação - PPGE da Universidade Estadual de Ponta Grossa - UEPG, Ponta Grossa, Pr.

Callai, H. C. Aprendendo a ler o mundo: a geografia nos anos iniciais do ensino fundamental. Cadernos do Cedes, 25(66), 227-247, 2005.

Cardoso, G. M. M. Trajetória formativa: entrelaçando saberes... estudo do meio como lugar de aprendizagem do/discente. Avaliação, 14(3), 713-726, 2009. Disponível em: <http://www.scielo.br/pdf/aval/v14n3/a11v14n3.pdf $>$.

Cavalcanti, L. S. A geografia escolar e a cidadania: ensaios sobre o ensino de geografia para a vida urbana cotidiana. Campinas, São Paulo: Papirus, 2008.

Cavalcanti, L. S. A Geografia e a realidade escolar contemporânea: avanços, caminhos, alternativas. In: Anais do Primeiro Seminário Nacional Currículo em Movimento. Belo Horizonte: Perspectivas Atuais, 2010. p. 1-16.

Delval, J. A escola possível: democracia, participação e autonomia. Campinas: Mercado das Letras, 2007. 
Fischer, F. Psicologia social do ambiente. Lisboa: Instituto Piaget, 1994.

Freire, P. Pedagogia da autonomia. São Paulo: Paz e Terra, 1996.

Freire, P. Pedagogia da indignação: cartas pedagógicas e outros escritos. São Paulo: Editora UNESP, 2000.

Freire, P. Pedagogia do oprimido. Rio de Janeiro: Paz e Terra, 2005.

Freire, P. À sombra desta mangueira. São Paulo: Olho d'Água, 2006.

Furth, H. G. Piaget e o conhecimento: fundamentos teóricos. Rio de Janeiro: Forense Universitária, 1974.

Giroux, H. Teoria crítica e resistência em educação: para além das teorias de reprodução. Petrópolis: Vozes, 1986.

Gumes, S. M. L. Construção da conscientização socioambiental: formulações teóricas para o desenvolvimento de modelos de trabalho. Paidéia, 15(32), 345-354, 2005. Disponível em: $<$ http://www.scielo.br/scielo.php?pid=S0103$-863 X 2005000300004 \&$ script $=$ sci_arttext $>$.

Hintz, B. B.; Callai, H. C.; Moraes, M. M. O estudo do lugar: construção da cidadania na escola. In: Anais do Salão do Conhecimento: Ciência, Tecnologia e Desenvolvimento Social. Ijuí. Salão do Conhecimento, 1, 1-6, 2014. Disponível em: <https://www.revistas.unijui.edu.br/index.php/ salaoconhecimento/article/view/3867/3247>.

Kuhnen, A. Percepção ambiental. In: Cavalcante, S.; Elali, G. A. (Orgs.). Temas básicos em Psicologia Ambiental. Petrópolis: Vozes, 2011. p. 250-266.

Kuhnen, A.; Higuchi, M. I G. Campos de encontro da psicologia e educação na construção de comportamentos socioambientais. Utopia y Praxis Latinoamericana, 14(44), 101-108, 2009. Disponível em: <http:// www.scielo.org.ve/scielo.php?script=sci_arttext\&pid $=\mathrm{S} 1315-52162009000100008>$.

Lakatos, E. M.; Marconi, M. Metodologia Científica. 4. ed. São Paulo: Atlas, 2006.

Layrargues, P. P. Para onde vai a educação ambiental? O cenário político-ideológico da educação ambiental brasileira e os desafios de uma agenda política crítica contra-hegemônica. Revista Contemporânea de Educação, 4, 398-421, 2012. Disponível em: <https://revistas.ufrj.br/ index.php/rce/article/view/1677>.
Layrargues, P. P.; Lima, G. F. C. Mapeando as macrotendências político-pedagógicas da educação ambiental contemporânea no Brasil. In: Anais do VI Encontro de Pesquisadores em Educação Ambiental. Ribeirão Preto, 1-15, 2011. Disponível em: <http://www.icmbio.gov.br/ educacaoambiental/images/stories/biblioteca/educacao_ ambiental/Layrargues_e_Lima_-_Mapeando_as_macro-tend $\% \mathrm{C} 3 \% 83 \% \mathrm{C} 2 \%$ AAncias_da_EA.pdf $>$.

Leff, E. Saber ambiental: sustentabilidade, racionalidade, complexidade, poder. Petrópolis, RJ: Vozes, 2001.

Lestinge, S.; Sorrentino, M. As contribuições a partir do olhar atento: estudos do meio e a educação para a vida. Ciência \& Educação, 14(3), 601-619, 2008. Disponível em: $<$ http://www.scielo.br/scielo.php?script=sci_arttext\& pid $=$ S1516-73132008000300015>.

Lima, G. F. C. Educação ambiental crítica: do socioambientalismo às sociedades sustentáveis. Educação e Pesquisa, 35(1), 145-163, 2009.

Lopes, C. S.; Pontuschka, N. N. Estudo do meio: teoria e prática. Geografia, 18(2), 173-191, 2009. Disponível em: $<$ http://www.uel.br/revistas/uel/index.php/geografia/article/ view/2360 $>$.

Loureiro. C. F. B. Trajetórias e fundamentos da educação ambiental. 2. ed., São Paulo: Cortez, 2006.

McLaren, P. A vida nas escolas: uma introdução à pedagogia crítica nos fundamentos da educação. Porto Alegre: Artes Médicas, 1997.

Melazo, G. C. Percepção ambiental e educação ambiental: uma reflexão sobre as relações interpessoais e ambientais no espaço urbano. Olhares \& Trilhas, 6, 45-51, 2005. Disponível em: <http://www.seer.ufu.br/index.php/olharesetrilhas/ article/view/3477/2560>.

Meyer, M. Â. A. Educação ambiental: uma proposta pedagógica. Em Aberto, 10(49), 40-45, 1991.

Monteiro de Oliveira, C. D. Do estudo do meio ao turismo geoeducativo: renovando as práticas pedagógicas em geografia. Boletim Goiano de Geografia, 26(1), 32-47, 2006. Disponível em: <http://www.redalyc.org/articulo. oa? id $=337127144002>$.

Paraná. Secretaria de Estado da Educação. Diretrizes Curriculares da Educação Básica/Geografia. Curitiba: SEED/ DEB-PR, 2008. Disponível em: <http://www.educadores. diaadia.pr.gov.br/arquivos/File/diretrizes/dce_geo.pdf $>$. 
Piaget, J. Para onde vai a educação? Rio de Janeiro: José Olympio Editora, 1973.

Piaget, J. O nascimento da inteligência na criança. Rio de Janeiro: Zahar; Brasília: INL, 1975.

Piaget, J. O Estruturalismo. São Paulo-Rio de Janeiro: Difel, 1979.

Piaget, J. Psicologia e Pedagogia. Rio de Janeiro: Forense, 1985.

Piaget, J. Psicologia da inteligência. Petrópolis: Vozes, 2013.

Pocinho, M; Figueiredo, J. P. SPSS: uma ferramenta para análise de dados (CD). In: Hernández Sampieri, R. et al. Metodologia de pesquisa. Tradução: Daisy Vaz de Moraes. 5. ed. Porto Alegre: Penso, 2013.

Reigota, M. Meio ambiente e representação social. 3. ed. São Paulo: Cortez, 1998.

Resende, M. M. S. O saber do aluno e o ensino de geografia. In: Vesentini, J. W. et al. Geografia e ensino: textos críticos. Campinas: Papirus, 83-115, 2007.

Rosso, A. J.; Becker, F.; Taglieber, J. E. A produção do conhecimento e a ação pedagógica. Educação e Realidade, 23(2), 63-82, 1998.

Santos, M. A natureza do espaço geográfico: técnica e tempo, razão e emoção. São Paulo: Hucitec, 1996.

Serpe, B. M. Educação, escola e instituições de contraturno social na cidade de Ponta Grossa: entrecruzamento de va- lores e representações por diferentes vozes. Ponta Grossa, Tese (Doutorado em Educação) - UEPG, 2015.

Serpe, B. M.; Rosso, A. J. Uma leitura piagetiana do papel da percepção na construção do conhecimento socioambiental em trilhas interpretativas. Schème: Revista Eletrônica de Psicologia e Epistemologia Genéticas, 3, 27-56, 2010. Disponível em: <http://www2.marilia.unesp.br/revistas/ index.php/scheme/article/view/1967/1619>.

Serpe, B. M.; Rosso, A. J.; Camargo, B. V. Percepção, cognição e aprendizagem socioambiental. Pesquisa em Educação Ambiental, 6, 79-99, 2011. Disponível em: <http://www. revistas.usp.br/pea/article/view/55926>.

Severino, A. J. Epistemologia, Psicologia e Educação. In: Borja, A. et al. Construtivismo em revista. São Paulo, FDE, 1994. p. 15-21.

Tornquist, C. S.; Lisboa, T. K.; Montysuma, M. F. Mulheres e meio ambiente. Estudos Feministas, 16(3), 865-869, 2010. Disponível em: <https://periodicos.ufsc.br/index.php/ref/ article/view/S0104-026X2010000300012>.

Torres, J. R.; Ferrari, N.; Maestrelli, S. R. P. Educação ambiental crítico-transformadora no contexto escolar: teoria $\mathrm{e}$ prática freireana. In: Loureiro, B. L.; Torres, J. R. (Orgs.). Educação Ambiental: dialogando com Paulo Freire. São Paulo: Cortez, 2014.

Tuan, Y. F. Topofilia: um estudo da percepção, atitudes e valores do meio ambiente. São Paulo: Difel, 1980. 